\title{
IN SITE INVESTIGATION AND STATISTICAL ANALYSIS OF LIVE LOADS OF LARGE SPAN FRAME STRUCTURE DURING CONSTRUCTION
}

\author{
Zhengwu $\mathrm{Ye}^{1, \mathrm{a}}$,Chaojun Jian ${ }^{2, \mathrm{~b} *}$, Changming $\mathrm{Hu}^{3, \mathrm{c}}$ and Yili Yuan ${ }^{4, \mathrm{~d}}$ \\ ${ }^{1,2,3,4}$ School of Civil Engineering, Xi' an University of Architecture and Technology, X'an,Shaanxi \\ 710055, China \\ a1532316811@qq.com,bjcj6513abc@163.com, ${ }^{\mathrm{c}} 13609161448 @ q q . c o m,{ }^{d} y y l 9007 @ 163 . c o m$
}

Key words: large span frame structure; live loads during construction; in site investigation; statistical analysis.

Abstract: Combine with a large span frame structure project , a survey on live loads of this building has been conducted, and the survey lasted the whole construction period of the building, the loads in the four phases of template erection, steel banding, concrete pouring and curing were recorded. According to the actual situation of the building, divided the building plan into $3 \mathrm{~m} \times 2 \mathrm{~m}$ grid, based on the result of survey and statistical analysis, it is found that the live loads submit to exponential distribution. And the parameters of exponential function were estimated, the standard value of live loads during construction was also suggested. The result of this paper can be used for the design of supporting structure for this kind of building and the subsequent research.

\section{Introduction}

The failure probability of concrete structure is different in construction, use and structure aging stage,the failure probability is much higher in construction stage than the other two stages ${ }^{[1]}$.

The strength of concrete structure is not enough to resist the function of construction loads,so scaffolds are used to support these loads as assistant support with the concrete at early stage.It's great significance to have comprehensive cognition of construction loads(especially live loads), so is improving security of construction stage.

Domestic and foreign scholars have done much researches about construction live loads.Scholars from Taiwan and America investigated 19 concrete buildings on the work site in 1990s.By injecting water into containers, they simulated the impact load when pouring concrete,and the maximum load was $50 \mathrm{kN} / \mathrm{m}^{2}$ [2].H.Ayoub[3] found the distribution function of live loads submit to Weilbull and Gamma by the survey on the work site.But the paper[4] found it submit to extreme I distribution by the same way. The paper[5-6]thought the distribution function of live loads submit to exponential distribution through in site investigation samely,and they suggested the standard value of live loads.Nan Xie combined 3D finite element influence surface and on-site measure to study live loads,and suggested that the standard value of live loads is $1.5 \mathrm{kN} / \mathrm{m}^{2}$. Tingsheng Zhao used effective bearing area of the support members as statistical objects with in-site measuring data,calculated statistical parameters of live loads and provided advice value.

So scholars usually investigate on the work-site to study live loads in construction stages,and they agreed that the accumulation loads(such as: materials, labors, equipment) is the most part of live loads, most of scholars also thought that the distribution function of accumulation loads submit to exponential distribution ${ }^{[5-6,9-10]}$.Although these scholars suggested the standard value of live loads, 
and so do the Technical Code for Safety of Forms in Construction(JGJ162-2008)and Technical Code for Safety of Steel Tubular Scaffold with Couplers in Construction(JGJ130-2011), most researches were for general form of concrete structure, it is necessary to study some special forms structure.

The section area of large span frame structure members is usually bigger than general form, this form structure usually means more materials and more steel re-bars, so the accumulation loads is more in same bearing area. And this would be more serious when meet a higher large span concrete structure which would need large amount of steel tubes for support scaffold systems, so more materials are on operation surface in concrete stage. The Fig.1 shows the loads on the floor at the four phases in construction period.

Fig.1 Loads condition of during construction

(1)mplate erection $\oslash$ steel banding $(\mathcal{)}$ Concrete pouring $\oplus$ Concrete pouring

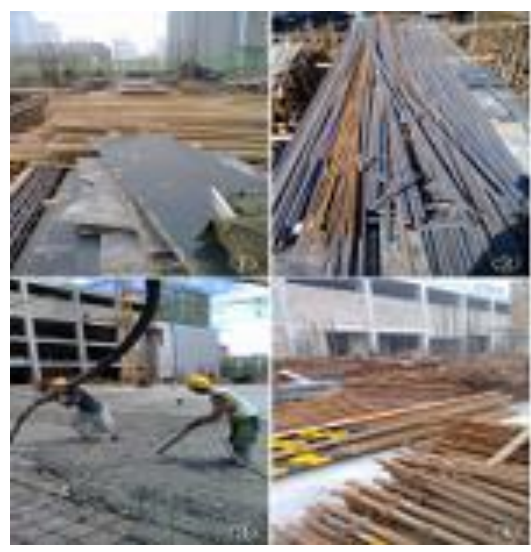

\section{Specification of Engineering}

The engineering that was investigated is a one building of a commercial complex, it is designed as a banquet hall and cinema for a five-star hotel. The building is a four floor building, and the height is $35.8 \mathrm{~m}$, the first and second are used for banquet halls and the third and fourth are for cinemas. This building is a concrete frame structure except for a steel truss roof,and the concrete members are all non-prestressed. The height of the first floor is $10.8 \mathrm{~m}$, the second is $10.4 \mathrm{~m}$, the third and the fourth is $8.8 \mathrm{~m}$, the structure span is $25.2 \mathrm{~m}$, the section of most primary beams is $0.55 \mathrm{~m} \times 1.5 \mathrm{~m}$, some is $0.35 \mathrm{~m} \times 1.4 \mathrm{~m}$, the secondary beams is $0.35 \times 1.4 \mathrm{~m}$, the distance between beams is $2.1 \mathrm{~m}$, the one floor build-up area of large span area is $1270 \mathrm{~m}^{2}$. The contractor possesses general contract level qualification. They operated the construction works with the sequence of template erection,steel erection,concrete pouring and curing,but in different area is possibly at different states, so we noted the work stage when counted the live loads in different areas.

With this investigation at the work-site, we found the difference between large span beams construction and general beams. Because of the deeper and complex of the beams,the construction sequence is not strictly followed the sequence of shuttering first and reinforcement later, the bottom and one side of slabs were built first,and then operated the reinforcement,built the other side of slab after reinforcement in order to enough operation space as the narrower and deeper section of beams.So the surface slabs of floors which had a priority to build would be as the materials bearing boards for others.It meant these area must bore more loads than the other areas. So the work state was definitely noted in different operation areas. 
The concrete pump was used to pour concrete,the beam also have a priority to the board,and the concrete of beams was cast distinctly-layer, the last layer of beams was cast together with the boards.

\section{The Statistical Method}

The every construction plan was the investigated objective,divided the building plan into $3 \mathrm{~m} \times 2 \mathrm{~m}$ grids. Along the length is $3 \mathrm{~m}$, and the vertical is $2 \mathrm{~m}$.Most scholars divided the build ing plan into $3 \mathrm{~m} \times 3 \mathrm{~m}$ grids for investigation ${ }^{[4-6,9-10]}$. The slab transfers the loads to the wooden beams, the beams transfer the loads to support bars, the loads on the slab were shared into the grids. According to this project,the length of the wooden beams is $3 \mathrm{~m}$,the distance between the structure beams is $2.1 \mathrm{~m}$, the net width of the slab is less than $3 \mathrm{~m}$, so the $3 \mathrm{~m} \times 2 \mathrm{~m}$ grid was adopted for the convenience of calculation.

The whole construction period was concerned,the four phases of template erection, steel

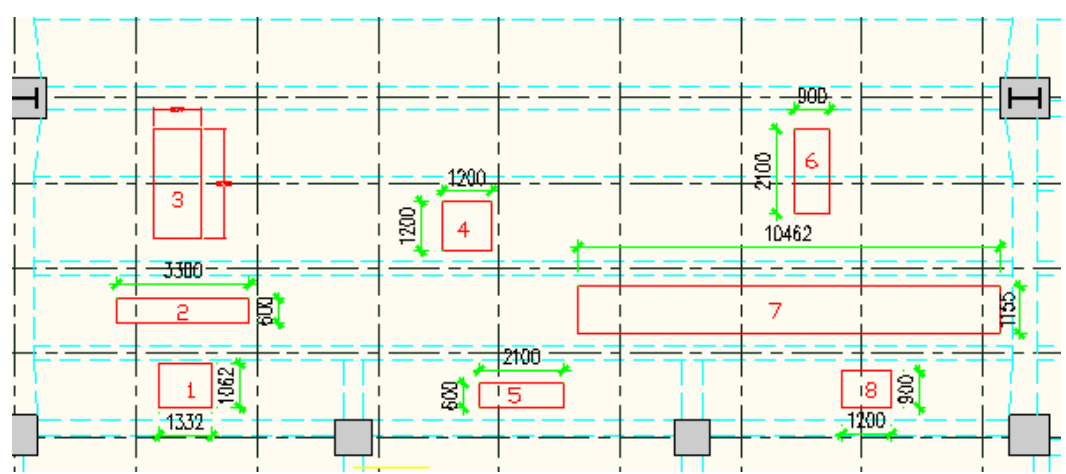

banding,concrete pouring and curing were focused.The loads on the slab were recorded every 2 hours at working time,the position and area of the loads were recorded as the Fig. 2 shows. The kind, size,quantity and other information were also recorded in detail as the Table 1 shows.

Fig. 2 Demonstration of construction live load investigation

Table1 Record of live load investigation

Date:

Floor:

\begin{tabular}{|c|c|c|c|c|c|c|c|}
\hline NO. & Kind & Size & Quantity & Area & Unit Weight & Weight $(\mathrm{kN})$ & phase \\
\hline 1 & Steel bar & $2.5 \mathrm{~m} \varphi 48^{*} 3.0$ & 141 & $2.5 \mathrm{~m}^{*} 2.6 \mathrm{~m}$ & $33.3 \mathrm{~N} / \mathrm{m}$ & 11.74 & forwork \\
\hline 2 & Wooden beam & $3 \mathrm{~m} 0.04^{*} 0.06$ & 180 & $3 \mathrm{~m} * 2.8 \mathrm{~m}$ & $5000 \mathrm{~N} / \mathrm{m}^{3}$ & 6.48 & forwork \\
\hline 3 & Re-bar & $9 \mathrm{~m} \varphi 25$ & 22 & $9 \mathrm{~m} * 0.35 \mathrm{~m}$ & $37.77 \mathrm{~N} / \mathrm{m}$ & 7.48 & reinforcement \\
\hline 4 & Re-bar & $\varphi 102 *(0.71+0.3)+2 * 0.1$ & 204 & $0.72 \mathrm{~m}^{*} 0.72 \mathrm{~m}$ & $6.04 \mathrm{~N} / \mathrm{m}$ & 2.74 & reinforcement \\
\hline$\ldots$ & $\ldots$ & $\ldots$ & $\ldots$ & $\ldots$ & $\ldots$ & \\
\hline
\end{tabular}

\section{Analysis of the statistical results}

Load of each element is the average value of the accumulation load on the corresponding gird. Element with no accumulation load is called non-load element, which is recorded separately. It can be seen from the distribution bar chart of live load during construction period (Fig.3) . 


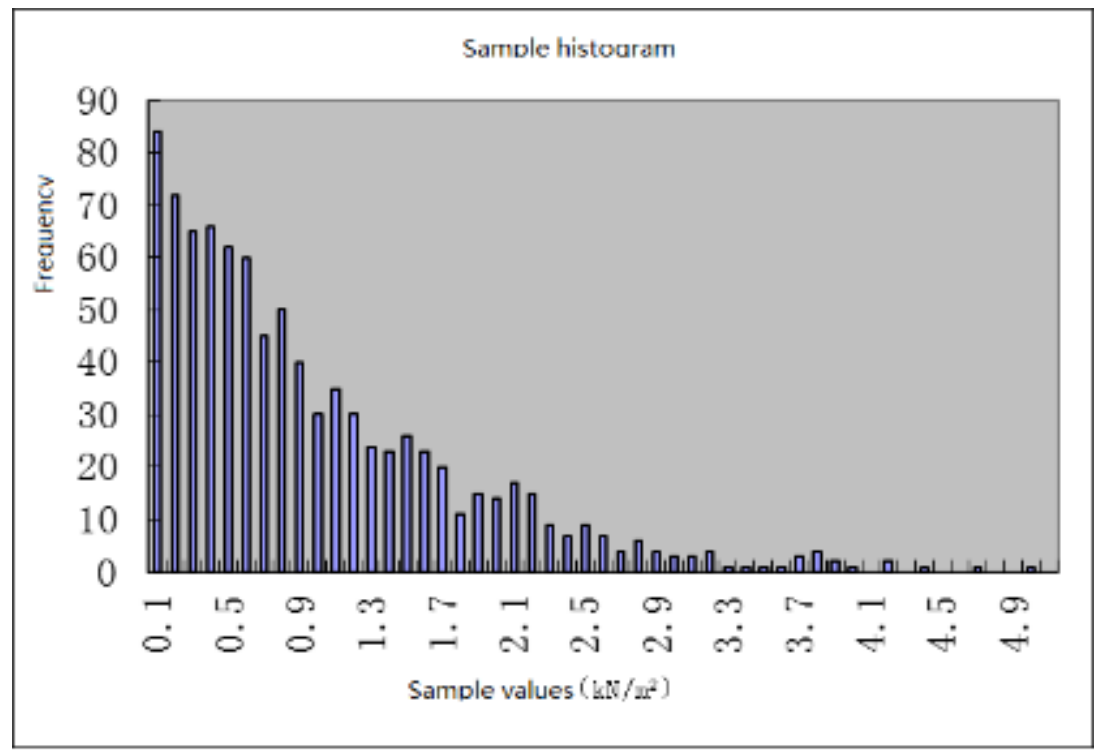

Fig.3 Bar chart of non-zero live load

That the distribution of the live load during construction period of large span frame structure is approximately exponential distribution. And the distribution function is

$$
F_{1}(x)=-\operatorname{lexp}(\lambda x)
$$

Probability density function is

$$
f_{1}(x)=\lambda \exp (-x), x>0
$$

After point estimate and $\chi^{2}$ goodness of fit test $(\alpha=0.05)^{[11]}$,got the result as the table2.

Table2 Statistical parameters of construction live loads

\begin{tabular}{c|c|c|c|c|c}
\hline$\lambda$ & $\sum \frac{\left(\mathrm{n}_{i}-n p_{i}\right)^{2}}{n p_{i}}$ & $\chi_{0.95}^{2}(k-r-1)$ & $\begin{array}{c}\text { Results } \\
\text { compared }\end{array}$ & $\begin{array}{c}\text { Statistics } \\
\text { means } \\
\left(\mathrm{kN} / \mathrm{m}^{2}\right)\end{array}$ & $\begin{array}{c}\text { Sample standard layer } \\
\left(\mathrm{kN} / \mathrm{m}^{2}\right)\end{array}$ \\
\hline 1.01 & 30.625 & 34.8 & Not refuse & 0.99 & 0.814 \\
\hline
\end{tabular}

Average values of the accumulation load during template erection, steel banding, and concrete pouring and curing period are shown in Table 3.

Table 3 the statistical average of the four phases

\begin{tabular}{|c|c|c|c|c|}
\hline Period & template erection & steel banding & $\begin{array}{c}\text { concrete } \\
\text { pouring }\end{array}$ & $\begin{array}{c}\text { concrete } \\
\text { curing }\end{array}$ \\
\hline Average value $\left(\mathrm{kN} / \mathrm{m}^{2}\right)$ & 0.77 & 1.11 & 0.17 & 1.24 \\
\hline
\end{tabular}

It can be seen from the accumulation load values of the four period that accumulation load is 
the highest during concrete curing period, and subsequently the steel bar binding period, the template erection period, and finally the concrete pouring period. The statistic result accords with the real condition. The reason for this difference between different periods is the different construction properties and the different accumulation materials. During concrete curing period, a large number of steel tubes were needed for the construction of the high scaffold, thus the accumulation load was high. During steel bar banding period, accumulation materials were mainly steel bars, while wood keels and planks were the main accumulation materials during template erection period. As for concrete pouring period, workers and a few construction instruments were the main reason for the accumulation load. Load caused by concrete pouring and vibrating are included in this paper. Some reference papers recommended a value of $2.0 \mathrm{kN} / \mathrm{m}^{2}$ for this part of load ${ }^{[12]}$.

Taking non- load element into account, the overall probability density function of the live load during the entire construction is

$$
F_{0}(x)=p_{0}+\left(1-p_{0}\right) F_{1}(x) .
$$

In this formula, $p_{0}=\frac{N_{0}}{N}$ is the proportion of the non-load element; $N_{0}$ is the quantity of non-load element; $N$ is the quantity of all elements.

According to statistics, $p_{0}$ equals 0.278 .

As shown in Fig.4 and Fig.5, the distribution function and probability density function of the live load during construction period which take non-load element into account were obtained.

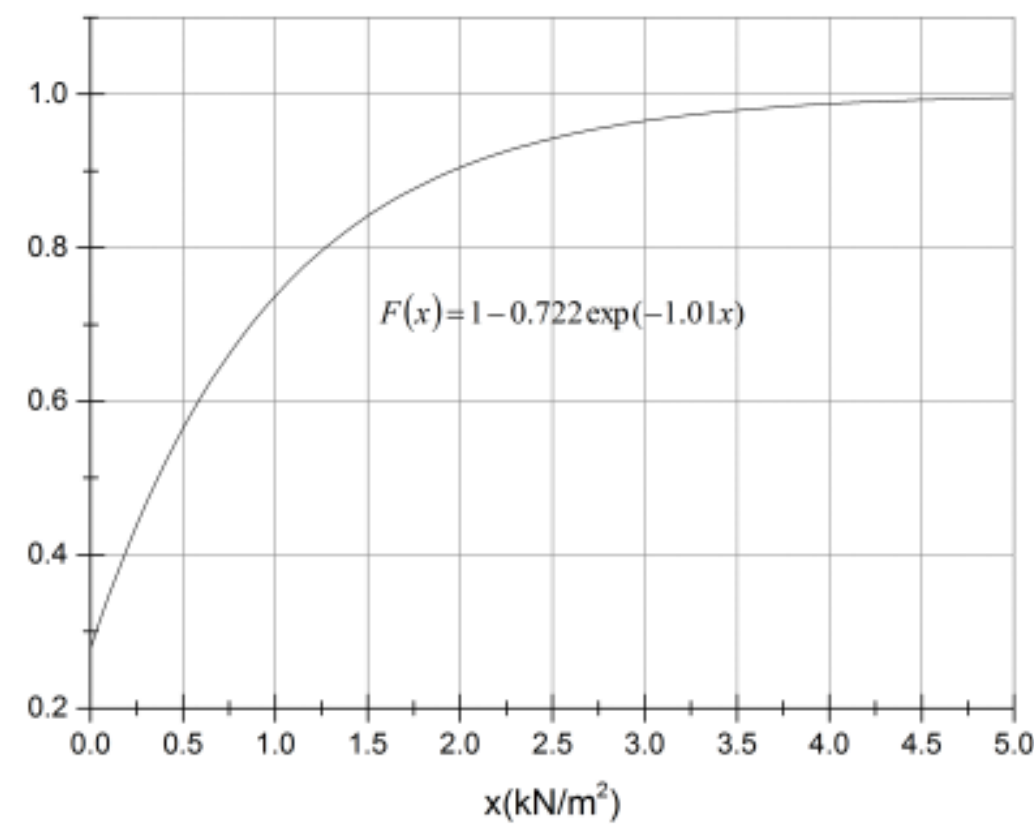

Fig.4 Probability distribution function $F(x)$ of live loads during construction

According to this probability density function and the determination method of the load standard value during service stage of a structure, the following equation was obtained. 


$$
F(X)=\int_{0}^{X} f(x) d x \geq 0.95 .
$$

Solution of the equation is $\mathrm{X}=2.644 \mathrm{kN} / \mathrm{m}^{2}$.

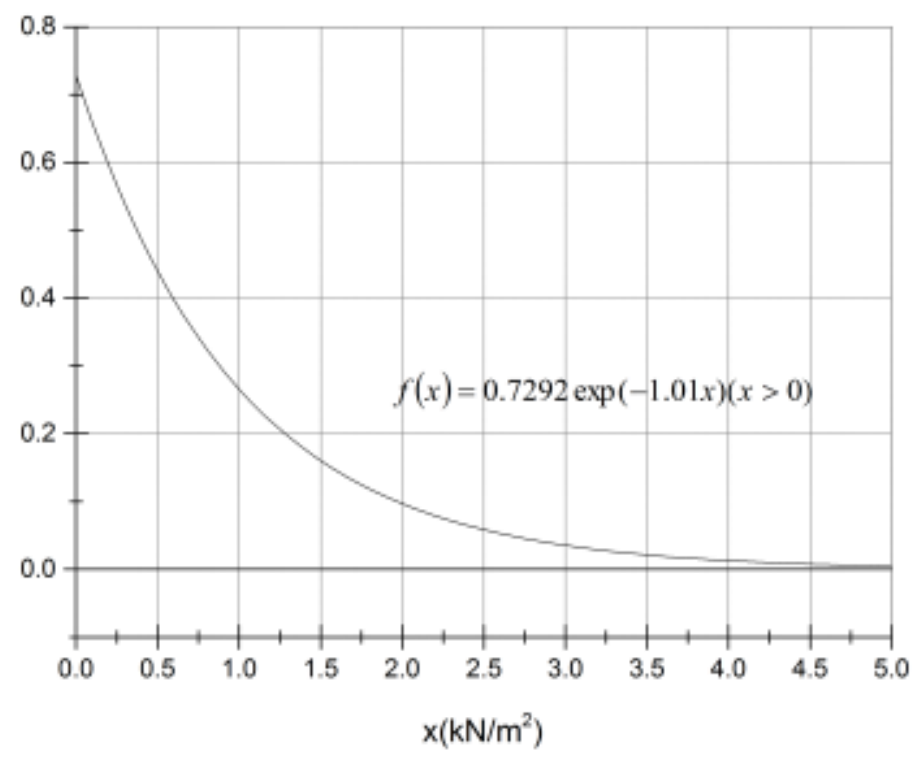

Fig. 5 Probability density function $f(x)$ of live loads during construction

In order to simplify the analysis, considering relevant papers and standards and the pattern of concrete pouring, $3.0 \mathrm{kN} / \mathrm{m}^{2}$ was recommended for the standard value of the live load of this large span frame structure during construction period.

\section{Conclusions and Recommendations}

By tracking the whole construction period of a large span frame structure, construction live load during template erection, steel banding, and concrete pouring and curing period were collected. According to the statistical data and analysis results, distribution regularity of the live load of this large span frame structure during construction period was described, and the proposed value of construction live load of this construction was given.

1.Accumulation load is the major component of the live load of large span frame structure, and most accumulation load were caused by heaped materials. Concrete curing period and steel bar binding period have the highest accumulation load in the light of statistical result. To avoid accumulation concentration, materials should be appropriately arranged, and be heaped when needed.

2.Distribution function of the live load of large span frame structure during construction period can be described by exponential function. Also, $3.0 \mathrm{kN} / \mathrm{m}^{2}$ was recommended for the standard value of the live load of this large span frame structure during construction period, which can be a reference for similar construction works.

3.The working surface was divided into several $3 \mathrm{~m} \times 2 \mathrm{~m}$ grids according to real condition for statistic work. 
Since the sample is not sufficient enough, instead of providing a construction live load value for the entire large span frame structure, the statistic result in this paper can only be a reference for the construction design of similar project or the further research on the construction live load of large span frame structure. Therefore, bigger and larger scope of statistic samples are required for a more general conclusion.

\section{References}

[1] Guofan Zhao, Liangwei Jin, Jinxin Gong.Structural Reliability Theory[M].Beijin:China Building Industry Press,2000.

[2] Rosowsky D V,Huang Y L,Chen W F et all.Modeling concrete placement loads during construction[J].Structural Engineering Review,1994,6(2):71-84.

[3] Ayoub H,Saeed Karsheas.Survey results for concrete construction live load on newly poured slabs[J].Journal of Structural Engineering,1994,120(5):1542-1564.

[4] Xiaoli Tong, Guofan Zhao.The investigation of loads during construction period of tall reinforced concrete buildings[R].Department of Civil Engineering, Dalian University of Technology,1997.

[5]Jijun Miao, Xianglin Gu, Xiaoming Fang.Statistical analys is of live load of tall concrete structure build ing during construction period[J].Building Structure,2002,32(3):7-9.

[6] Chuanmin Zhang,Dongping Fang et.In situ investigation and statistical analysis of live loads of reinforced concrete building during construction[J].Engineering Mechanics,2002,19(5):62-66.

[7] Nan Xie, Renzhong Liang,Hang Hu. Analysis of construction loads of formwork during concrete placement based on influence surface[J].Engineering Mechanics,2011,28(10):173-178.

[8] Tingsheng Zhao,Shuxun Li,Xianglin Gu.On-site measure and statistic of live load construction load of concrete building[J].Cons truction Technology,2005,34(7):63-65.

[9] Yuan Mei,Cangming Hu et.Statistical analysis of loads of supporting structure for tall and large false work during construction[J].Ind ustrial Construction,2010,40(2):41-46.

[10] Jun Zhao, Yulin Yang.Statistical analys is of live loads for reinforced concrete buildings construction[J].Journal of Guilin University of Technology[J].Statistics analysis of live loads for reinforced concrete buildings construction,2010,30(3):356-359.

[11] Chuqiang Zhuang, Yasen Wu.Applied mathematical statistics foundation[M].Guangzhou:South China University of Technology Press,2003.

[12] Jie Wang. The performance research of mixed erection formwork support system under 
bi-direction load.Xi'an: Xi' an University of Architecture and Technology,2013. 